\title{
Prevalence and determinants of frailty in the absence of disability among older population: a cross sectional study from rural communities in Nepal
}

Uday Narayan Yadav ${ }^{1,2^{*}}$, Man Kumar Tamang ${ }^{2,3}$, Tarka Bahadur Thapa ${ }^{2}$, Hassan Hosseinzadeh ${ }^{4}$, Mark Fort Harris ${ }^{1}$ and Krishna Kumar Yadav ${ }^{2}$

\begin{abstract}
Background: Longevity and frailty have significant implications for healthcare delivery. They increase demands for healthcare service and surge risk of hospitalization. Despite gaining global attention, determinants of frailty have remained unmeasured in the rural community settings in Nepal. This study aimed to address this gap by accessing the prevalence and determinants of frailty in the absence of disability among older population living in rural communities in eastern Nepal.

Methods: We conducted a cross-sectional analytical study of 794 older adults aged $\geq 60$ living in the rural part of Sunsari and Morang district of eastern Nepal between January and April in 2018. Multi-stage cluster sampling was applied to recruit the study participants. Study measures included socio-demographics; Frail Non-disabled scale (FiND) measuring frailty, Barthel's Index measuring basic activities of daily living and Geriatric depression scale. Determinants of frailty in the absence of disability were identified using generalized estimating equation (GEE).

Results: About $65 \%$ of the participants self-reported the presence of frailty in the absence of disability. In the adjusted models, those from underprivileged ethnic groups, lack of daily physical exercise, presence of depressive symptoms and those not getting enough social support from family were found to be significantly associated with frailty among older participants.

Conclusions: The prevalence of frailty in the absence of disability was high among rural community old population living in eastern Nepal. Our findings suggest that need of frailty awareness (both for clinicians and general public), so as to avoid negative consequences. To reduce the healthcare burden early screening frailty in primary care has potentials to prevent implications of frailty in Nepal.
\end{abstract}

Keywords: Depression, Frailty, Older, Prevalence, Primary care

\section{Background}

Longer life is valuable, and existing evidence suggests that that older people today are experiencing better health compared to previous generation [1]. However, physical and mental capacities are often decreased by increasing aging [2].

Nepal, a low-income country like other countries has achieved significant progress in reducing the infant and

\footnotetext{
* Correspondence: u.yadav@unsw.edu.au; unyadav1@gmail.com ${ }^{1}$ Centre for Primary Health Care and Equity, UNSW, Sydney, Australia

${ }^{2}$ Forum for Health Research and Development, Dharan, Nepal

Full list of author information is available at the end of the article
}

premature mortality [3]. This has led to better life expectancy for both women [71.88 years] and men [68.66 years] in 2016 [4]. Now healthy aging is an emerging challenge for public health in Nepal [5].

Frailty is a common geriatric syndrome which is characterized by age-associated declines in physiologic reserve and function, leading to increased vulnerability, ranging from adverse health outcomes (falls, disability, and institutionalization) to death [6,7]. Epidemiological studies on frailty mostly conducted in high-income countries $[9,10]$, have associated frailty with depression, malnutrition, polypharmacy, poor hearing, lack of exercise, poor family 
support, presence of co-morbidities and poorer selfreported health status $[8,11-15]$. A study from Nepal conducted among 253 beneficiaries of Gurkha Welfare Trust, a welfare centre using a clinical frailty scale reported $46.2 \%$ of frailty among participants aged $\geq 60$ years old [16].

Epidemiological transitions show the increase in the number of older populations in Nepal [4]. Available data suggest that the quality of life of older population is undermined by changes in traditional family structure, modernization, lack of career and the presence of longterm disease [4] This can cumulatively increase the risk of frailty. Despite this, there is scarceness of evidence on the frailty in the absence of disability among older population in the community setting of rural Nepal. This study is an attempt to address this gap by exploring prevalence and determinants of frailty in the absence of disability among older population in the rural part of Sunsari and Morang district of eastern Nepal.

\section{Methods}

\section{Study designs and participants}

This was a community-based cross-sectional study conducted among older people adults aged $\geq 60$ years old living in the Morang and Sunsari districts of Nepal, carried out between January and April in 2018. A multi-stage cluster sampling approach was used to select study subjects. The sample size of 847 was calculated based on following assumptions: prevalence $=50 \%$, sampling error $=5.0 \%, \mathrm{CI}=$ $95.0 \%$, design effect $=2$ and non-response rate $=5.0 \%$. A total of 794 of the sampled eligible participants responded to the study. In the first stage, four Rural Municipalities (RMs) were randomly selected from the list of RMs within each Morang and Sunsari District. Second, five wards were randomly selected in each of the selected RMs. Table 1 presents the details of sampling strategy. Finally, individuals were selected randomly from the list of eligible subjects provided by the RMs representative and were interviewed by the trained interviewers in the community setting.

The eligible study population included adults aged $\geq 60$ years old who had lived in the community for the past year and were Nepali nationals and willing to complete study survey. Informed consent was obtained from all the study participants (thumb impressions from those who were not able to read and write) and was informed about the right to free to withdraw or opt out at any point without any penalty. The exclusion criteria included residing in nursing care, being mentally disabled (clinically proved schizophrenia, bipolar mood disorder), being seriously ill (terminal illness like cancer, chronic kidney disease), having a hearing disability or being unable to communicate. The study protocol was approved by the Ethics Committee of Nepal Health Research Council, Ministry of Health.

\section{Data collection and study variables}

The study used both semi-structure interviews and validated survey instrument to collect data.

\section{Primary measurement}

Frailty was the primary outcome, which was measured using "Frail non-Disabled" (FiND) questionnaire [17], the novel instrument designed to measure frailty syndrome and disability in community-dwelling older persons.

The FiND questionnaire $(\alpha=0.82)$ contains five sections ranging from $\mathrm{A}$ to $\mathrm{E}$. Items $\mathrm{A}$ and $\mathrm{B}$ measure mobility disability whereas item $C$ measures weight loss; item D measures exhaustion; and item E measures level of physical activity. Participants were categorized "disabled" if item $A+B \geq 1$, "frail" if $A+B=0$ and $C+D+$ $\mathrm{E} \geq 1$ and "robust" if $\mathrm{A}+\mathrm{B}+\mathrm{C}+\mathrm{D}+\mathrm{E}=0$.

\section{Independent variable measurement}

Independent variable included age group; gender; ethnicity; religion; marital status; living arrangement; literacy status; occupation; monthly personal income; smoking habit; alcohol drinking habit; tobacco chewing habit; physical activity; presence of any co-morbidities; depressive symptoms; activities of daily living; ; and getting enough support from family members/caregivers. Measurement of concentration problems included "failing to recall the position of objects and forgetting to perform activities in time by the older people if instructed by family members or caregivers in the last 30 days".

These co-variates are described in the published paper authored by Yadav et.al [18]. Barthel's scale measuring activities of daily living [19] was used to assess daily living activities. Depressive symptoms were assessed using a short version of the geriatric depression scale [20].

The English version of the survey was first translated to Nepali and then translated (forward-backward translation) back to English by two researchers to check the consistency. A small community level workshop was conducted to arrive to final version of the tool by considering the remarks from older population.

\section{Statistical analyses}

The statistical analyses were performed using the Statistical Package for Social Sciences (SPSS 23.00). Normality of the data was assessed using both visually (histogram with normal curve) and normality test (Shapiro-Wilk test). An association between the categorical variables was checked using Chi-square test. Variables that were significantly associated ( $p$-value $\leq 0.05$ ) with the outcome variables in univariate analysis were considered in the stepwise multivariable analysis. The generalized estimating equation (GEE) was used to identify the factors associated with frailty in absence of disability among the older population. 
Table 1 Sampling details of this study

\begin{tabular}{|c|c|c|}
\hline & $\begin{array}{l}\text { \# of older people in each } \\
\text { randomly selected ward } \\
\text { of RM }\end{array}$ & $\begin{array}{l}\text { Number of participants } \\
\text { selected from each } \\
\text { selected ward }\end{array}$ \\
\hline \multicolumn{3}{|c|}{ Sunsari District } \\
\hline \multicolumn{3}{|c|}{ Rural Municipality 1} \\
\hline Ward a & 640 & 18 \\
\hline Ward b & 702 & 20 \\
\hline Ward c & 806 & 23 \\
\hline Ward d & 774 & 22 \\
\hline Ward e & 543 & 17 \\
\hline \multicolumn{3}{|c|}{ Rural Municipality 2} \\
\hline Ward a & 663 & 19 \\
\hline Ward b & 636 & 18 \\
\hline Ward c & 723 & 21 \\
\hline Ward d & 601 & 18 \\
\hline Ward e & 627 & 19 \\
\hline \multicolumn{3}{|c|}{ Rural Municipality 3} \\
\hline Ward a & 1004 & 29 \\
\hline Ward b & 732 & 22 \\
\hline Ward c & 888 & 26 \\
\hline Ward d & 844 & 24 \\
\hline Ward e & 592 & 17 \\
\hline \multicolumn{3}{|c|}{ Rural Municipality 4} \\
\hline Ward a & 784 & 23 \\
\hline Ward b & 683 & 20 \\
\hline Ward c & 709 & 21 \\
\hline Ward d & 814 & 24 \\
\hline Ward e & 684 & 20 \\
\hline \multicolumn{3}{|c|}{ Morang District } \\
\hline \multicolumn{3}{|c|}{ Rural Municipality1 } \\
\hline Ward a & 640 & 20 \\
\hline Ward b & 702 & 20 \\
\hline Ward c & 806 & 23 \\
\hline Ward d & 774 & 22 \\
\hline Ward e & 722 & 21 \\
\hline \multicolumn{3}{|c|}{ Rural Municipality2 } \\
\hline Ward a & 936 & 27 \\
\hline Ward b & 804 & 23 \\
\hline Ward c & 601 & 17 \\
\hline Ward d & 508 & 16 \\
\hline Ward e & 65 & 19 \\
\hline \multicolumn{3}{|c|}{ Rural Municipality 3} \\
\hline Ward a & 832 & 24 \\
\hline Ward b & 701 & 20 \\
\hline Ward c & 824 & 24 \\
\hline Ward d & 502 & 15 \\
\hline Ward e & 802 & 23 \\
\hline
\end{tabular}

Table 1 Sampling details of this study (Continued)

\begin{tabular}{cll}
\hline & $\begin{array}{l}\text { \# of older people in each } \\
\text { randomly selected ward } \\
\text { of RM }\end{array}$ & $\begin{array}{l}\text { Number of participants } \\
\text { selected from each } \\
\text { selected ward }\end{array}$ \\
\hline Rural Municipality 4 & 23 \\
Ward a & 784 & 20 \\
Ward b & 683 & 22 \\
Ward c & 709 & 24 \\
Ward d & 814 & 23 \\
Ward e & 789 & 23
\end{tabular}

Proportionate sampling was adopted to reach the sample size in each rural mucipality of the respective districts

\section{Results}

Study sample characteristics

Complete data were collected from 794 study participants. The mean age of the respondents was $70.16( \pm$ 8.54 ) years old for male and 69.70 years old $( \pm 8.86)$ for females. Table 2 shows the characteristics of the study population. Socio-demographic findings showed that majority of the study participants were in the age group of 60-69 years (55\%), were from Brahmin/Chhetri/Thakuri ethnic group (38\%), 79\% were ascribed to Hindu religion, married (53\%), living with family members (73\%), illiterate (80\%), unemployed (53\%) and had no personal monthly income (66\%). Majority of the study participants had a smoking and tobacco chewing history. Only $22.92 \%$ were ever involved in physical exercise. The variables measuring health status showed that $61.58 \%$ of the study participants had at least two chronic condition (combination of hypertension, cardiovascular disease, arthritis, respiratory disease etc) and more than half $(55 \%)$ had depressive symptoms. About $47 \%$ needed assistance in daily living activities and 39\% had memory concentration problems in past 30 days prior to a survey.

\section{Prevalence of frailty}

The prevalence of frailty, disability and robustness were examined using of the FiND questionnaire. Of total 794 samples, 65\% [CI: 61.68-68.32] were "frail" (non-disabled), 28\% [24.88-31.12] were "disable" and only 7\% [CI: 5.23-8.77] reported being robust (Table 3).

\section{Factors associated with frailty}

Table 4 presents multivariable regression results indicating the factors independently associated with frailty. After adjusting for socio-demographic variables, being from any of three underprivileged ethnic groups [Indigenous: $\mathrm{aOR}=$ 1.07, CI: 1.01-1.14; Dalit: $\mathrm{aOR}=1.13, \mathrm{CI}$ : $1.03-1.14$ and, Madhesi: $\mathrm{OOR}=1.07, \mathrm{CI}: 1.00-1.14]$, lack of daily physical exercise $[\mathrm{aOR}=1.22, \mathrm{CI}: 1.15-1.30]$, presence of depressive symptoms $[\mathrm{aOR}=1.06, \mathrm{CI}: 1.02-1.10]$ and those not getting enough social support from family $[\mathrm{aOR}=1.04, \mathrm{CI}$ : 1.01-1.08] were significantly associated frailty. 
Table 2 Participants' characteristics $(n=794)$

\begin{tabular}{|c|c|c|c|}
\hline \multirow[t]{2}{*}{ Variables } & \multicolumn{2}{|c|}{$\begin{array}{l}\text { Presence of non-disabled } \\
\text { frailty }\end{array}$} & \multirow[t]{2}{*}{$P$-value } \\
\hline & Yes & No & \\
\hline \multicolumn{4}{|c|}{ Age group (years) } \\
\hline $60-69$ & $315(61.0)$ & $125(45.0)$ & \multirow[t]{3}{*}{0.000} \\
\hline $70-79$ & $146(28.3)$ & $89(32.0)$ & \\
\hline$\geq 80$ & $55(10.7)$ & $64(23.0)$ & \\
\hline \multicolumn{4}{|l|}{ Gender } \\
\hline Male & $268(51.9)$ & $132(47.5)$ & \multirow[t]{2}{*}{.13} \\
\hline Female & $248(48.1)$ & $146(52.5)$ & \\
\hline \multicolumn{4}{|l|}{ Ethnicity } \\
\hline Brahmin/chhetri/thakuri & $41(7.9)$ & $28(10.1)$ & \multirow{5}{*}{0.000} \\
\hline Aadiwasi/Janajatis & $175(33.9)$ & $123(44.2)$ & \\
\hline Dalit & $104(20.2)$ & $53(19.1)$ & \\
\hline Madheshi & $169(32.8)$ & 74 (26.6) & \\
\hline Other ethnical groups & $27(5.2)$ & $0(0)$ & \\
\hline \multicolumn{4}{|l|}{ Religion } \\
\hline Hinduism & $403(78.1)$ & $222(79.9)$ & \multirow{4}{*}{.03} \\
\hline Buddhism & $8(1.6)$ & $11(4.0)$ & \\
\hline Islam & $91(17.6)$ & $34(12.2)$ & \\
\hline Christianity & $14(2.6)$ & $11(4.0)$ & \\
\hline \multicolumn{4}{|l|}{ Marital status } \\
\hline Married & $292(56.6)$ & $133(47.8)$ & \multirow[t]{2}{*}{.04} \\
\hline $\begin{array}{l}\text { Widow/widower/divorced/ } \\
\text { separated/unmarried }\end{array}$ & $224(43.4)$ & $145(52.2)$ & \\
\hline \multicolumn{4}{|l|}{ Living arrangement } \\
\hline $\begin{array}{l}\text { Stays with family including } \\
\text { spouse }\end{array}$ & $389(75.4)$ & $194(69.8)$ & \multirow[t]{3}{*}{.21} \\
\hline Stays with spouse only & $88(17.1)$ & $60(21.6)$ & \\
\hline Stays alone & $39(7.6)$ & $24(8.6)$ & \\
\hline \multicolumn{4}{|l|}{ Literacy status } \\
\hline Illiterate & $398(77.1)$ & $238(85.6)$ & \multirow[t]{2}{*}{.005} \\
\hline Literate & $118(22.9)$ & $40(14.4)$ & \\
\hline \multicolumn{4}{|l|}{ Occupation } \\
\hline Employed & $248(48.1)$ & $116(41.7)$ & \multirow{3}{*}{.15} \\
\hline Unemployed & $259(50.2)$ & $159(57.2)$ & \\
\hline Retired/Pensioner & $9(1.7)$ & $3(1.1)$ & \\
\hline \multicolumn{4}{|l|}{ Monthly personal income (NPR) } \\
\hline No income $<$ NRs.500 & $340(64.9)$ & $184(35)$. & \multirow[t]{3}{*}{.007} \\
\hline NRs.500-2000 & 79 (56.4) & $61(43.6)$ & \\
\hline >NRs. 2000 & $97(74.6)$ & $33(25.4)$ & \\
\hline \multicolumn{4}{|l|}{ Smoking habit } \\
\hline Never smoker & $194(37.6)$ & $106(38.1)$ & \multirow[t]{2}{*}{.94} \\
\hline Having smoking history & $322(62.4)$ & $172(61.9)$ & \\
\hline \multicolumn{4}{|l|}{ Alcohol drinking habit } \\
\hline Never drinker & $321(62.2)$ & $183(65.8)$ & \multirow[t]{2}{*}{.35} \\
\hline Having alcohol drinking history & $195(37.8)$ & 95 (34.2) & \\
\hline
\end{tabular}

Table 2 Participants' characteristics $(n=794)$ (Continued)

\begin{tabular}{lccc}
\hline Variables & \multicolumn{2}{l}{$\begin{array}{l}\text { Presence of non-disabled } \\
\text { frailty }\end{array}$} & \\
\cline { 2 - 3 } & Yes & No & \\
\hline Tobacco chewing habit & & & \\
Never tobacco chewer & $256(49.6)$ & $155(55.8)$ & .87 \\
Having tobacco chewing history & $260(50.4)$ & $123(44.2)$ & \\
Physical activity & & & \\
Daily physical exercise & $97(18.8)$ & $85(30.6)$ & .000 \\
No physical exercise at all & $419(81.2)$ & $193(69.4)$ & \\
Presence of any co-morbidities & & & \\
Yes & $296(57.4)$ & $193(68.4)$ & .001 \\
No & $220(42.6)$ & $85(30.6)$ & \\
Depressive symptoms' & & & \\
Yes & $259(50.2)$ & $184(66.2)$ & .000 \\
No & $257(49.8)$ & $94(33.8)$ & \\
Activities of daily living & & & \\
Dependence & $169(32.8)$ & $204(73.4)$ & 0.000 \\
Independent & $347(67.2)$ & $74(26.6)$ & \\
Memory concentration problems in last 30 days & & .000 \\
Yes & $169(32.8)$ & $139(50.0$ & \\
No & $347(67.2)$ & $139(50.0)$ & \\
Getting enough support from family & members/caregivers & \\
Yes & 80 & 40 & \\
No & 436 & 238 & \\
\hline
\end{tabular}

\section{Discussion}

The growing aging population increases the demand for and use of older adult(s)-friendly health services in Nepal [4]. The National Health Policy in 2014 aimed to deliver quality health services to the all of the citizens (Universal Health Coverage) and provide basic health services at free of cost [21] However, delivery of health services conducive to the aging population health like frailty is not envisaged well. In light of this, there is a yawning gap in the assessment of non-disabled frailty and its determinants among older adults in Nepal. This study aimed to determine the prevalence of frailty and its determinants among older adults living in the rural communities in Eastern Nepal. To the best of our knowledge, this is the first study to explore frailty in the absence of disability among the geriatric population residing in the community settings of Nepal.

Table 3 Community-dwelling older persons with frailty syndrome with FiND screening tool $(n=794)$

\begin{tabular}{llll}
\hline & Category & $\mathrm{n}$ & $\%[95 \% \mathrm{Cl}]$ \\
\hline FiND & Robust & 56 & $7.0[5.23-8.77]$ \\
& Frail (non-disabled) & 516 & $65.0[61.68-68.32]$ \\
& Disabled & 222 & $28.0[24.88-31.12]$ \\
\hline
\end{tabular}


Table 4 Factors independently associated with frailty in the absence of disability among rural communities' old population

\begin{tabular}{|c|c|c|}
\hline Variables & $\begin{array}{l}\text { Univariate model } \\
\text { OR [95\% Cl] }\end{array}$ & $\begin{array}{l}\text { Multivariate model } \\
\text { aOR[95\% Cl] }\end{array}$ \\
\hline \multicolumn{3}{|l|}{ Marital status } \\
\hline Married & 1 & 1 \\
\hline $\begin{array}{l}\text { Others Widow/widower/ } \\
\text { divorced/separated/unmarried }\end{array}$ & $1.04(1.00-1.09)$ & $1.00(.96-1.04)$ \\
\hline \multicolumn{3}{|l|}{ Ethnicity } \\
\hline Brahmin/chhetri/thakuri & 1 & 1 \\
\hline Indigenous group & $1.16(1.11-1.21)$ & $1.07(1.01-1.14)$ \\
\hline Dalit & $1.19(1.09-1.31)$ & $1.13(1.03-1.14)$ \\
\hline Madheshi & $1.10(1.04-1.16)$ & $1.07(1.00-1.14)$ \\
\hline Other ethnical groups & .000 & .000 \\
\hline \multicolumn{3}{|l|}{ Religion } \\
\hline Hinduism & $1.09(1.06-1.12)$ & $.98(.84-1.15)$ \\
\hline Buddhist & $1.46(1.23-1.74)$ & $.98(.84-1.14)$ \\
\hline Islam & $1.30(1.11-1.51)$ & $1.14(.91-1.42)$ \\
\hline Christianity & 1 & 1 \\
\hline \multicolumn{3}{|l|}{ Daily physical exercise } \\
\hline Yes & 1 & 1 \\
\hline No & $1.29(1.21-1.37)$ & $1.22(1.15-1.30)$ \\
\hline \multicolumn{3}{|l|}{ Depressive symptoms } \\
\hline No & 1 & 1 \\
\hline Yes & $1.08(1.04-1.13)$ & $1.06(1.02-1.10)$ \\
\hline \multicolumn{3}{|c|}{$\begin{array}{l}\text { Getting enough support from family } \\
\text { members/caregivers }\end{array}$} \\
\hline Yes & 1 & 1 \\
\hline No & $1.08(1.04-1.12)$ & $1.04(1.01-1.08)$ \\
\hline
\end{tabular}

Our finding shows that the prevalence of frailty was $65 \%$ among the older population. Frailty is a recognized health problem of older people health and this finding is in line with strong rationale highlighting the need of evidence of frailty in Low and Middle-Income Countries (LMICs) [22]. In line with our finding, Devkota et al., reported $46.2 \%$ of Nepalese pensioners had a degree of frailty [16]. The population previously studied are Nepalese origin exBritish army whereas our study involves the general Nepalese citizen of the community setting. Our estimate is higher than the estimates of frailty from a single multicounty study including China (13.1\%), India (55.5\%) and a nationally represented study from Singapore $(5.7 \%)[23,24]$. This might be explained by the fact that these studies used different frailty instruments. Such discrepancies indicate that there is a need to develop an internationally standardized frailty assessment measurement detecting frailty among older populations. In our study setting, the high rate of morbidity may relate to "over reporting of health problems" to get better health care from the health service provided by government of
Nepal. This indicates that health decision and policy makers should be aware of social desirability bias while designing any intervention aimed to improve healthy wellbeing or health ageing.

Our results showed that older people from underprivileged ethnic groups, those with depressive symptoms and not doing daily physical exercise, and those not getting enough social support from family were found to have frailty in the absence of disability in rural older population. Notably, we found increased odds of frailty among three underprivileged ethnic groups as compared to higher caste, which may be related to the poor sociocultural and socio-economic class of the caregiver of the older people population. Caste /Ethnicity have been a central feature in Nepal to describe level of poverty, poor health literacy and health status [25]. The condition of underprivileged group is miserable in the rural setting as compared to higher caste as they do not have equitable access to the prevailing service because of multiple barriers [26]. This could be related to poor purchasing and consumption capacity for food, which might have affected their nutritional status and, therefore put older people at higher risk of frailty. Higher castes in Nepal have the highest per capita income as compared to lower castes [27]. In light with our findings, previous research has showed the linkage between socio-economic disadvantage with higher allostatic load "known as wear and tear" of the body, which in turn related to frailty $[28,29]$.

Among older adults who have no social support from family members progressive were frail compared to their counterparts. This can be explained by the fact; lack of social support makes the older people prey for psychological illness reflecting that vulnerability worsens their health status. The literatures support the fact that lack of social support makes the older people feel helpless and lonely, which might affect consumption of health food, poor appetite and poor adherence to the medicines [30]. In total, this affects the nutrition status of the older people. Theories of environmental gerontology state that people are influenced by an ongoing interchange between the individual and their physical and social environment [31]. Our findings are supported by the findings from study that revealed increased social support was associated with less-steep increases of frailty over time [32]. Similarly, Lurie et al. found an association between social support and lower frailty levels 10 to 13 years later among older adults less than 65 years of age [33].

Our finding in terms of depressive symptoms and frailty is in line with existing literature [12, 13]. Presence of depressive symptoms is often correlated with the increased risk of frailty [34]. In relation to physical activity, our finding showed that lack of physical exercises increases the odds of frailty by more than two times [35, 36]. The results from the population-based cohort study showed that 
physically active older adults as compared to their physically inactive counterparts found to be associated with lower all-cause mortality among the frail, pre-frail and robust individuals [37]. Similarly, the findings from multifactorial Frailty Intervention Trial (FIT) found that included balance, strength, and endurance exercise showed the lower prevalence on frailty and improved mobility among the intervention arm compared with the control group [38]. It is worth mentioning that physical exercises have positive impact on the individual functional life and improving health consequences of the frail people. Therefore, exercise could be a key modifiable intervention for improving physical function and in preventing and reducing the frailty.

Despite invaluable findings, this study has some limitations, which should be considered in any interpretation and generalization. The participants were from eight rural municipalities of Morang and Sunsari district, Nepal; thus, the results can be only generalized to the studied district with caution. Our findings relied on selfreported data, where social- desirability bias may have occurred. Moreover, the measurement of lifestyle factors like alcohol use, smoking and physical activity was not done using any standard instrument. Further, since this study was cross-sectional, causal relationships cannot be established. The notifiable strength of this study is: large sample size with response rate more than 90\%, strong methodology and adoption of FiND questionnaire for the first time in Nepalese settings and, we recommend more studies using this tool.

\section{Conclusions}

Noting the high prevalence in the community, we suggest the screening of frailty at primary health care could be a ground-breaking work to avoid the beginning of an irreversible disabling process. We also emphasize on frailty awareness on preventive aspects (both for clinicians and general public), so as to avoid negative consequences, to reduce the healthcare burden. Further, we recommend the need for longitudinal follow-up national-level studies on frailty among older population in Nepal. Additionally, our finding in particular suggest that community-based intervention having physical activity as essence component can be researched to see the promising outcomes suggested by the literatures of other settings.

The evidence generated in this study shows that nondisabled frailty is very common among the older population in rural communities in Nepal and evidence-based strategies are needed to address this growing public health challenge.

\section{Abbreviations}

aOR: Adjusted Odds Ration; Cl: Confidence Interval; FiND: "Frail non-Disabled" questionnaire; GEE: Generalized estimating equation; RMs: Rural

Municipalities; SPSS: Statistical Product and Service Solutions

\section{Acknowledgments}

We would like to thank all the participants of this study and loca government bodies. Authors acknowledge the assistance of Prof. Renuka Viswanathan (Director, Aged \& Extended Care Service, University of Adelaide) for her technical inputs in this project.

\section{Authors' contributions}

Conceived and designed the experiments: UNY, MKT, TBT, HH, MFH, KKY Performed field work: UNY, MKT, TBT, KKY. Analysed the data: UNY, MFH, HH. Wrote the paper: UNY, MKT, TBT, HH, MFH, KKY. All authors read and approved the final manuscript.

\section{Funding}

The authors received funding from Nepal Health Research Council, Ministry of Health, Government of Nepal (Provincial grant). The funders had no role in the study design, data collection and analysis of the data.

\section{Availability of data and materials}

The datasets used and/or analysed during the current study are available from the corresponding author on reasonable request.

\section{Ethics approval and consent to participate}

The study was approved by the Institutional Review Board of Nepal Health Research Council, Government of Nepal, Ministry of Health, Kathmandu. After detailed information, all study participants gave their written informed consent.

\section{Consent for publication}

Not applicable.

\section{Competing interests}

The authors declare that they have no competing interests.

\section{Author details}

${ }^{1}$ Centre for Primary Health Care and Equity, UNSW, Sydney, Australia. ${ }^{2}$ Forum for Health Research and Development, Dharan, Nepal. ${ }^{3}$ Queensland Brain Institute, The University of Queensland, Brisbane, Australia. ${ }^{4}$ University of Wollongong, Wollongong, Australia.

Received: 4 February 2019 Accepted: 23 September 2019

Published online: 22 October 2019

\section{References}

1. Crimmins EM, Beltrán-Sánchez H. Mortality and morbidity trends: Is there compression of morbidity? J Gerontol B Psychol Sci Soc Sci. 2011; $66 \mathrm{~b}(1): 75-86$

2. World Report on Ageing and Health [Report]. Geneva: World Health Organisation. 2015. Available from https://apps.who.int/iris/bitstream/ handle/10665/186463/9789240694811_eng.pdf;jsessionid=3748929F111 BCF73E853D4C44FED863B? sequence $=1$.

3. Yadav UN. Health governance in Nepal: how to deliver effective and quality health services? Policy brief; 2016

4. Nepal - Life expectancy at birth. 2016. https://countryeconomy.com/ demography/life-expectancy. Accessed 1 Feb 2019.

5. Yadav UN, Paudel G. Prevalence and associated factors of elder mistreatment: a cross sectional study from urban Nepal. Age Ageing. 2016; 45(5):609-13.

6. Fried LP, Xue QL, Cappola AR, Ferrucci L, Chaves P, Varadhan R, Guralnik JM, Leng SX, Semba RD, Walston JD, et al. Nonlinear multisystem physiological dysregulation associated with frailty in older women: implications for etiology and treatment. J Gerontol A Biol Sci Med Sci. 2009;64a(10):1049-57.

7. Fried LP, Tangen CM, Walston J, Newman AB, Hirsch C, Gottdiener J, Seeman T, Tracy R, Kop WJ, Burke G, et al. Frailty in older adults: evidence for a phenotype. J Gerontol A Biol Sci Med Sci. 2001;56(3):M146-56.

8. Buttery AK, Busch MA, Gaertner B, Scheidt-Nave C, Fuchs J. Prevalence and correlates of frailty among older adults: findings from the German health interview and examination survey. BMC Geriatr. 2015;15:22.

9. Soysal P, Stubbs B, Lucato P, Luchini C, Solmi M, Peluso R, Sergi G, Isik AT, Manzato E, Maggi S, et al. Inflammation and frailty in the older people: a systematic review and meta-analysis. Ageing Res Rev. 2016;31:1-8. 
10. Lorenzo-López L, Maseda A, de Labra C, Regueiro-Folgueira L, RodríguezVillamil JL, Millán-Calenti JC. Nutritional determinants of frailty in older adults: a systematic review. BMC Geriatr. 2017;17(1):108.

11. Nguyen TN, Cumming RG, Hilmer SN. A review of frailty in developing countries. J Nutr Health Aging. 2015;19(9):941-6.

12. Pegorari MS, Tavares DMS. Factors associated with the frailty syndrome in elderly individuals living in the urban area. 2014;22(5):874-82. https://doi. org/10.1590/0104-1169.0213.2493. Available from: https://www.ncbi.nlm.nih. gov/pmc/articles/PMC4292678/.

13. Aguilar-Navarro SG, Amieva H, Gutiérrez-Robledo LM, Avila-Funes JA. Frailty among Mexican community-dwelling older people: a story told 11 years later. The Mexican health and aging study. Salud Publica Mex. 2015; 57(suppl1):S62-9.

14. Yassuda MS, Lopes A, Cachioni M, Falcao DV, Batistoni SS, Guimaraes W, Neri AL. Frailty criteria and cognitive performance are related: data from the FIBRA study in Ermelino Matarazzo, Sao Paulo, Brazil. J Nutr Health Aging. 2012;16(1):55-61

15. Cruz DTD, Vieira MT, Bastos RR, Leite ICG. Factors associated with frailty in a community-dwelling population of older adults. Rev Saude Publica. 2017;51:106

16. Devkota S, Anderson B, Soiza RL, Myint PK. Prevalence and determinants of frailty and associated comorbidities among older Gurkha welfare pensioners in Nepal. Geriatr Gerontol Int. 2017;17(12):2493-9.

17. Cesari M, Demougeot L, Boccalon H, Guyonnet S, Van Kan GA, Vellas B, Andrieu S. A self-reported screening tool for detecting community-dwelling older persons with frailty syndrome in the absence of mobility disability: the FiND questionnaire. PLoS One. 2014;9(7):e101745. https://doi.org/10.1371/ journal.pone.0101745 eCollection 2014.

18. Yadav UN, Tamang MK, Paudel G, Kafle B, Mehta S, Chandra Sekaran V, Gruiskens JRH. The time has come to eliminate the gaps in the underrecognized burden of elder mistreatment: a community-based, crosssectional study from rural eastern Nepal. PLoS One. 2018;13(6):e0198410. https://doi.org/10.1371/journal.pone.0198410 Barthel Activities of Daily Living (ADL) Index. Occasional paper (Royal College of General Practitioners). 1993(59):24.

19. Mahoney Fl, Barthel DW. Functional evaluation: the Barthel index. Md State Med J. 1965:14:61-5.

20. Sheikh Jl, Yesavage JA. Geriatric Depression Scale (GDS): recent evidence and development of a shorter version. Clin Gerontol. 1986;5(1/2):165-73.

21. National Health Policy of Nepal-2014. Department of Health Services, Government of Nepal, Kathmandu. Available from: https://dohs.gov.np/wpcontent/uploads/2014/04/NHP-2074_policy-01.pdf.

22. Siriwardhana DD, Hardoon S, Rait G, Weerasinghe MC, Walters KR. Prevalence of frailty and prefrailty among community-dwelling older adults in low-income and middle-income countries: a systematic review and metaanalysis. BMJ Open. 2018;8(3):e018195. https://doi.org/10.1136/bmjopen2017-018195.

23. Biritwum RB, Minicuci N, Yawson AE, Theou O, Mensah GP, Naidoo N, Wu F, Guo $Y$, Zheng $Y$, Jiang $Y$, et al. Prevalence of and factors associated with frailty and disability in older adults from China, Ghana, India, Mexico, Russia and South Africa. Maturitas. 2016;91:8-18.

24. Vaingankar JA, Chong SA, Abdin E, Picco L, Chua BY, Shafie S, Ong HL, Chang S, Seow E, Heng D, et al. Prevalence of frailty and its association with sociodemographic and clinical characteristics, and resource utilization in a population of Singaporean older adults. Geriatr Gerontol Int. 2017;17(10): 1444-54.

25. Subedi M. Caste/ethnic dimensions of change and inequality: implications for inclusive and affirmative agendas in Nepal. Nepali J Contemp Stud. 2016:XVI(1-2) https://www.cmi.no/file/3893-.pdf. Accessed 18 Apr 2019.

26. Lawyers' Association for Human Rights of Nepalese Indigenous Peoples (LAHURNIP), The International Work Group for Indigenous Affairs (IWGIA). Study on the socio-economic status of indigenous peoples in Nepal. 1st ed. Kathmandu: Lawyers' Association for Human Rights of Nepalese Indigenous Peoples (LAHURNIP); 2014. Available from: https://www.iwgia.org/images/ publications/0712_social-economic-status-of-indigenous-peoples-of-nepal. pdf.

27. Asian Development Bank. Country poverty analysis (detailed) Nepal. https:// www.adb.org/sites/default/files/linked-documents/cps-nep-2013-2017-padetailed.pdf. Accessed 18 Apr 2019.

28. Robertson T, Popham F, Benzeval M. Socioeconomic position across the lifecourse \& allostatic load: data from the west of Scotland Twenty-07 cohort study. BMC Public Health. 2014;14:184. https://doi.org/10.1186/14712458-14-184.

29. Gale CR, Booth T, Starr JM, Deary IJ. Intelligence and socioeconomic position in childhood in relation to frailty and cumulative allostatic load in later life: the Lothian birth cohort 1936. J Epidemiol Community Health. 2015. https://doi.org/10.1136/jech-2015-205789.

30. Duppen D, Van der Elst MCJ, Dury S, Lambotte D, Donder LD, D-SCOPE. The social Environment's relationship with frailty: evidence from existing studies (systematic review). J Appl Gerontol. 2019;38(1):3-26. https://doi.org/10. 1177/0733464816688310.

31. Wahl H, Oswald F. Environmental perspectives on ageing. In: Tinker A, editor. The SAGE handbook of social gerontology. London: Sage; 2010. p. $111-24$

32. Peek MK, Howrey BT, Ternent RS, Ray LA, Ottenbacher KJ. Social support, stressors, and frailty among older Mexican American adults. J Gerontol Ser B Psychol Sci Soc Sci. 2012;67:755-64.

33. Lurie I, Myers V, Goldbourt U, Gerber Y. Perceived social support following myocardial infarction and long-term development of frailty. Eur J Prev Cardiol. 2015;22:1346-53

34. Veronese N, Stubbs B, Fontana L, Trevisan C, Bolzetta F, Rui MD, Sartori L, Musacchio E, Zambon S, Maggi S, et al. A comparison of objective physical performance tests and future mortality in the older people people. J Gerontol A Biol Sci Med Sci. 2017;72(3):362-8.

35. Higueras-Fresnillo S, Cabanas-Sánchez V, Lopez-Garcia E, Esteban-Cornejo I, Banegas JR, Sadarangani KP, Rodríguez-Artalejo F, Martinez-Gomez D. Physical activity and association between frailty and all-cause and cardiovascular mortality in older adults: population-based prospective cohort study. J Am Geriatr Soc. 2018;66(11):2097-103.

36. Cameron ID, Fairhall N, Langron C, Lockwood K, Monaghan N, Aggar C, Sherrington C, Lord SR, Kurrle SE. A multifactorial interdisciplinary intervention reduces frailty in older people: randomized trial. BMC Med. 2013;11:65.

37. Blodgett J, Theou O, Kirkland S, Andreou P, Rockwood K. The association between sedentary behaviour, moderate-vigorous physical activity and frailty in NHANES cohorts. Maturitas. 2015;80(2):187-91.

38. Gurung L, Paudel G, Yadav U. Health service utilization by older people population in urban Nepal: a cross-sectional study. J Manmohan Mem Inst Health Sci. 2016;2:27-36

\section{Publisher's Note}

Springer Nature remains neutral with regard to jurisdictional claims in published maps and institutional affiliations.

\section{Submit your next manuscript to BioMed Central and we will help you at every step:}

- We accept pre-submission inquiries

- Our selector tool helps you to find the most relevant journal

- We provide round the clock customer support

- Convenient online submission

- Thorough peer review

- Inclusion in PubMed and all major indexing services

- Maximum visibility for your research

Submit your manuscript at www.biomedcentral.com/submit
C Biomed Central 